\title{
RELEVANSI KOMPETENSI TEKNIK GAMBAR MANUFAKTUR DI SMK MUHAMMADIYAH 2 JATINOM TERHADAP KEBUTUHAN INDUSTRI
}

\author{
Ahmad Nur Arifin ${ }^{1}$, Febrianto Amri R. ${ }^{2}$ \\ 1,2 Pendidikan Teknik Mesin, Fakultas Teknik, Universitas Negeri Yogyakarta \\ ahmad8c12200@gmail.com
}

\begin{abstract}
This research aims to identify the relevance of competency of manufacture drawing subject at SMK Muhammadiyah 2 Jatinom compared to the industrial competency needs. The research is a descriptive research. The subjects of the study were students, a teacher of manufacture drawing subject, and drafters working in the manufacturing industry. Questionnaires were used as data collection method. Data were analyzed using statistical descriptive analysis by percentages. The result shows that the relevance of competency of manufacture drawing subject to the industrial competency needs is $74.3 \%$, which is in the category of "medium" relevancy. The learning materials of manufacture drawing subject being taught to the students is $52.3 \%$ (highly relevant), while the learning materials itself is $47.7 \%$ (medium relevancy).
\end{abstract}

Keywords: relevance, industrial competence, manufacture drawing competence

\begin{abstract}
ABSTRAK
Tujuan penelitian ini adalah untuk mengetahui relevansi kompetensi mata pelajaran Teknik Gambar Manufaktur di SMK Muhammadiyah 2 Jatinom dengan kebutuhan kompetensi di industri. Penelitian ini merupakan penelitian deskriptif. Subjek penelitian ini adalah siswa, guru Teknik Gambar Manufaktur dan drafter pada industri manufaktur. Metode pengumpulan data menggunakan angket. Analisa data yang digunakan adalah statistik analisis deskriptif dengan persentase. Hasil penelitian menunjukkan bahwa relevansi kompetensi mata pelajaran Teknik Gambar Manufaktur di SMK Muhammadiyah 2 Jatinom terhadap kompetensi kebutuhan industri adalah sebesar $72 \%$ dan termasuk dalam kategori cukup relevan. Materi yang sudah diperoleh oleh siswa tentang mata pelajaran TGM 52,3\% yang termasuk kategori sangat relevan, sedangkan 47,7\% materi yang diperoleh siswa termasuk kategori cukup relevan.
\end{abstract}

Kata kunci: relevansi, kompetensi industri, kompetensi teknik gambar manufaktur

\section{PENDAHULUAN}

Keterkaitan antara SMK dengan industri merupakan hal yang sangat penting karena tujuan akhir dari lulusan SMK adalah mampu bekerja sesuai keahlian kerja di industri. Menciptakan lulusan yang berkualitas dan mengurangi angka pengangguran harus didukung dengan kerja sama antara kedua belah pihak.

Indonesia saat ini memiliki jumlah penduduk lebih dari 253 juta jiwa. Persaingan dunia kerja yang semakin ketat, berbanding terbalik dengan jumlah lapangan kerja, membuat tingkat pengangguran di Indonesia tinggi. Data dari Badan Pusat Statistik (BPS) menunjukkan suatu angka yang mengkhawatirkan, ditinjau dari latar belakang pendidikan, nampak pengangguran terbesar berasal dari lulusan SMK. Tabel tentang jumlah pengangguran berdasarkan pendidikan dilihat pada Tabel 1.

Permasalahan rendahnya penyerapan tenaga kerja dalam sektor manufaktur ini disebabkan oleh rendahnya produktivitas. Rendahnya kualitas pekerja menyebabkan produktivitas dan daya saing rendah. Dilihat secara mendalam, rata-rata tingkat pendidikan pekerja diIndonesia masih rendah, sekitar $63 \%$ didominasi oleh tamatan SMA kebawah. Selain itu, ketidak sesuaian antara kebutuhan industri manufaktur terhadap tenaga kerja 
dengan pendidikan dan pelatihan menyebabkan perusahaan/industri mengalami kesulitan untuk mendapatkan tenaga kerja yang berkualitas.

Tabel 1. Persentase Pengangguran Berdasarkan Tingkat Pendidikan Tahun 2016

\begin{tabular}{llc}
\hline No. & Pendidikan Terakhir & Persentase (\%) \\
\hline 1. & SD ke Bawah & 2,88 \\
2. & SMP & 5,75 \\
3. & SMA & 8,73 \\
4. & SMK & 11,11 \\
5. & Diploma I-III & 6,04 \\
6. & Universitas & 4,87 \\
\hline
\end{tabular}

Sekolah Menengah Kejuruan (SMK) bertujuan untuk mempersiapkan generasi mandiridan siap kerja dimana dalam pembelajarannya peserta didik dibekali kemampuan dan pengetahuan agar dapat hidup mandiri (Rachmat Jati Puruasdi, 2016: 535). SMK merupakan garda terdepan dalam mencetak tenaga kerja di Indonesia, namun sejauh ini ternyata masih banyak tamatan SMK yang menjadi pengangguran. Banyaknya lulusan SMK yang menganggur dapat dimungkinkan karena ketidaksesuaian antara pengetahuan dan skill yang didapat siswa di SMK dengan apa yang dibuuhkan dunia industri. SMK seharusnya dapat menyesuaikan materi pembelajarannya dengan kompetensi yang dibutuhkan industri dengan mengacu pada standard kompetensi yang telah diakui dan berskala nasional yaitu Standard Kompetensi Kerja Nasional Indonesia (SKKNI). SKKNI adalah rumusan kemampuan kerja yang mencakup semua aspek yang relevan dengan pelaksanaan tugas dan syarat jabatan yang ditetapkan sesuai dengan ketentuan peraturan perundang-undangan yang berlaku. SKKNI sendiri dikeluarkan oleh Badan Nasional Sertifikasi Profesi (BNSP) yang merupakan badan independen yang bertanggung jawab kepada presiden dan memiliki kewenangan sebagai otoritas sertifikasi personil dan bertugas melaksanakan sertifikasi kompetensi profesi bagi tenaga kerja. Dengan kata lain BNSP menentukan kelayakan sumber daya manusia pada suatu bidang perkerjaan.
SKKNI terdiri berbagai bidang kompetensi salah satunya adalah dalam bidang menggambar teknik pada industri manufaktur. Setiap industri mempunyai tuntutan yang berbeda kepada para drafter, karena produk yang dibuat dan peralatan yang digunakan berbeda antara satu perusahaan dengan perusahaan yang lain. Sehingga jika SMK ingin menyesuaikan kemampuan yang diajarkan dengan kompetensi yang dibutuhkan industri, maka perlu mengacu pada SKKNI sebagai standard umum dan mengetahui penggunaannya di industri. Berdasarkan observasi di jurusan permesinan SMK Muhammadiyah 2 Jatinom, mata pelajaran Teknik Gambar Menufaktur (TGM) diajarkan pada siswa kelas XI. Pebelajaran tersebut menggunakan silabus kurikulum 2013 namun belum mengacu pada SKKNI. Sedangkan standar yang digunakan industri mengacu pada SKKNI. Sehingga materi yang didapatkan oleh siswa belum maksimal, padahal industri menuntut agar siswa ketika praktik kerja industri sudah menguasai dalam bidang gambar teknik manufaktur. Menurut Wahyu Nursalim (2016: 279) perlu adanya komunikasi dan kerjasama yang intensif antara pihak sekolah dengan industri agar tenaga kerja yang dihasilkan dari lulusan SMK memiliki kompetensi sesuai dengan apa yang diharapkan oleh pihak industri.

Peran gambar teknik dalam industri manufaktur sangatlah penting, karena gambar teknik digunakan untuk menunjukan rencana sebuah objek yang akan dibangun atau dipasang (Giesecke, 2001: 4). Selain digunakan untuk merencanakan gambar juga digunkan untuk sarana pengawetan yang berfungsi untuk menyuplai bagian-bagian produk untuk perbaikan atau untuk diperbaiki (Sujiyanto, 2000: 1). Pentingnya gambar teknik di industri seharusnya SMK paham mengenai hal itu, sebagai acuan mengembangkan kompetensi siswa. Terlebih perkembangan jaman saat ini untuk pembuatan rencana dan pembuatan produk secara total, dari pembuatan rencana ke produksi, 
menerbitkan daftar bahan teknik, pemasaran dan laporan biaya seluruhnya sudah menggunakan komputer (Computer-Aided Design) (Giesecke, 2000: 15-16). Pelaksanaan mata pelajaran TGM yang diajarkan ke siswa SMK mengacu pada kurikulum 2013, siswa diajarkan mengambar menggunakan komputer. Namun dalam kurikulum tersebut materi yang diajarkan tidak mencakup kemampuan menggambar 3D, padahal kemampuan ini sangat penting untuk dikuasai oleh siswa, karena di industri gambar 3D mempunyai peran besar terhadap pengerjaan suatu barang.

Dari uraian di atas pentingnya kurikulum dalam menentukan keberhasilan pendidikan di SMK. Untuk itu, kurikulum SMK harus disusun sebaik mungkin agar tujuan SMK dapat terpenuhi yakni menghasilkan lulusan untuk bekerja. Dengan demikian kurikulum SMK harus disesuaikan dengan kebutuhan dunia kerja sebagai pengguna lulusan SMK sehingga lulusan SMK nantinya memiliki kemampuan atau kompetensi yang dibutuhkan saat memasuki dunia kerja dan pada akhirnya lulusan SMK dapat terserap di dunia kerja. Berdasarkan permasalah diatas, maka tujuan dari penelitian ini adalah untuk mengetahui tingkat relevansi kompetensi mata pelajaran TGM SMK Muhammadiyah 2 Jatinom terhadap kebutuhan industri manufaktur.

\section{METODE}

Penelitian ini merupakan jenis penelitian deskriptif, dimana peneliti tidak melakukan manipulasi atau memberikan perlakuanperlakuan tertentu terhadap variabel. Peneliti hanya memaparkan apa yang terjadi dalam sebuah lapangan atau wilayah tertentu.(Suharsimi Arikunto, 2013: 3).

Penelitian ini dilaksanakan pada bulan Februari s/d Juli 2017 di SMK Muhammadiyah 2 Jatinom dan industri tempat praktik kerja industri siswa SMK Muhammadiyah 2 Jatinom.
Populasi pada penelitian ini adalah industri manufaktur tempat praktik kerja industri SMK 2 Muhammadiyah 2 Jatinom tahun ajaran 2016/2017 dan industri yang berlokasi di Klaten, yang dapat dilihat pada Tabel 2.

Tabel 2. Daftar Tempat Praktik Kerja Industri

\begin{tabular}{ll}
\multicolumn{1}{c}{ Industri } & \multicolumn{1}{c}{ Lokasi } \\
\hline CV. Harto Sejahtera & Boyolali \\
CV. Prima Tehnindo & Sukoharjo \\
CV. Wahyu Jaya & Katen \\
Bengkel Las "Hr" & Klaten \\
Pedro Mx Faxtory & Klaten \\
Bintang Jaya & Klaten \\
Jaya Abadi & Klaten \\
Bengkel Mekar & Klaten \\
Tri Dodo Jaya & Klaten \\
PT. Sari Warna Asli & Boyolali \\
CV. Kembar Jaya & Klaten \\
Bengkel Santoso Mtr & Klaten \\
CV. Marabunta Machin & Klaten \\
CV. Aneka Technics & Klaten \\
Bengkel Las Zidan & Klaten \\
Bengkel Kudus & Klaten \\
Hns Putra Bersaudara & Klaten \\
POLMAN Ceper & Klaten \\
CV. Besi Barokah & Karanganyar \\
Sarana Karya Mulya & Klaten \\
CV. Lumintu & Klaten \\
PT. Hanil Indonesia & Boyolali \\
Mitra Jaya Teknik & Klaten \\
Benkel Las Rd.18 & Klaten \\
Bengkel Las Zidan & Klaten \\
Bengkel As Rama Jaya & Klaten \\
CV. Metal Teknik Raya & Klaten \\
Bengkel Las Margoto & Klaten \\
Las. Sugiyanto & Klaten \\
Bengkel Las "Prima" & Klaten \\
Jaya Agung Mandiri & Klaten \\
Las. Munjalin & Klaten \\
Sumber Teknik & Klaten \\
Bengkel Las Mandiri & Klaten \\
PT. Aneka Adhilogam & Klaten \\
CV. Putra Sari Logam & Klaten \\
CV. Atma Jaya & Klaten \\
\hline & \\
\hline & \\
\hline
\end{tabular}

Penentuan sampel dalam penelitian ini menggunakan teknik purposive sampling. Teknik ini dilakukan karena pertimbangan keterbatasan waktu, tenaga, dan dana sehingga tidak dapat mengambil sampel yang besar dan jauh. Dari kriteria sample tersebut, maka diperoleh 5 industri sebagai tempat penelitian yang dapat dilihat pada Tabel 3 . 
Tabel 3. Daftar Industri Tempat Penelitian

\begin{tabular}{ll}
\hline \multicolumn{1}{c}{ Industri } & \multicolumn{1}{c}{ Lokasi } \\
\hline CV. Prima Tehnindo & Sukoharjo \\
CV. Tiga Marabunta & Klaten \\
PT. Aneka Adhi Logam & Klaten \\
CV. Putra Sari Logam & Klaten \\
PT. Atma Jaya & Klaten \\
\hline
\end{tabular}

Prosedur dalam penelitian ini meliputi: observasi untuk merumuskan masalah, menyusun landasan teori yang mendukung, menentukan populasi dan sampel penelitian, menyusun instrumen dan validasi instrumen, pengumpulan data, melakukan analisis data dan pembahasan, dan membuat kesimpulan dan saran.

Teknik pengumpulan data menggunakan angket tertutup dalam bentuk skalat likert dan wawancara tidak terstruktur yang bertujuan untuk mengetahui tingkat relevansi kompetensi mata pelajaran TGM SMK Muhammadiyah 2 Jatinom terhadap kebtuhan industri.

Teknik analisis data menggunakan analisis deskriptif yang disajikan dalam bentuk persentase. Data masing-masing responden dikumpulkan, dihitung, kemudian disusun dan dianalisis secara deskriptif dangan cara: menjumlahkan banyak nilai jawaban dari setiap kategori untuk masing-masing responden pada setiap standar kompetensi. Untuk mencari persentase setiap kelompok kompetensi yang dibutuhkan oleh industri menggunakan Persamaan 1. (Syofian Siregar, 2011: 9).

$X_{k d}=\frac{\sum F_{k d}}{N_{k d}} \times 100 \%$

Keterangan:

$X_{k d}=$ rata-rata persentase kompetensi dasar yang dibutuhkan industri setiap standar kompetensi.

$\sum F_{k d}=$ jumlah seluruh skor dari kompetensi dasar yang dipreoleh dari industri.

$N_{k d}=$ jumlah seluruh skor maksimal kompetensi dasar tiap standar kompetensi.

Dari hasil persentase kompetensi dasar yang dibutuhkan industri setiap kompetensi kemudian dijumlahkan dan dicari rata-rata dengan menggunakan Persamaan 2. (Syofian Siregar, 2011: 20).

$\bar{X}_{k}=\frac{X_{k d}}{N}$

Keterangan:

$\bar{X}_{k}=$ jumlah rata-rata persentase kompetensi dasar yang dibutuhkan industri setiap standar kompetensi.

$X_{k d} \quad=$ rata-rata persentase kompetensi dasar yang dibutuhkan industri setiap standar kompetensi.

$N \quad=$ jumlah seluruh industri.

Untuk mengetahui relevansi kompetensi teknik pengelasan yang diajarkan di SMK Muhammadiyah 2 Jatinom dengan kebutuhan kompetensi di industri pengelasan di DIY, maka setiap skor butir yang didapat di konversikan kedalam kriteria. Kriteria tersebut didasarkan pada Tabel 4.

Tabel 4. Kriteria Tingkat Relevansi

\begin{tabular}{lc}
\hline \multicolumn{1}{c}{ Kriteria } & Skor (\%) \\
\hline Relevan & $76-100 \%$ \\
Cukup Relevan & $56-75 \%$ \\
Kurang Relevan & $40-55 \%$ \\
Tidak Relevan & $<40 \%$ \\
\hline
\end{tabular}

\section{HASIL DAN PEMBAHASAN}

Tabel 5. Kompetensi Relevan

\begin{tabular}{ll}
\hline \multicolumn{1}{c}{ Kompetensi } & $\begin{array}{c}\text { Tingkat } \\
\text { Relevansi }\end{array}$ \\
\hline $\begin{array}{l}\text { Sistem variabel disesuaikan dengan } \\
\text { prosedur operasi standar }\end{array}$ & $81,3 \%$ \\
Pilihan perintah di kostumasi sesuai & $80 \%$ \\
prosedur operasi standar & \\
Menggambar dengan menggunakan & $83,8 \%$ \\
kemampuan penuh sistim piranti lunak & \\
Entiti gambar terhubung dengan sistim & $77,5 \%$ \\
bank data yang menampung \\
atribut/sifat entiti untuk menyesuaikan \\
tuntutan kerja \\
$\begin{array}{l}\text { Pandangan detail dibuat menggunakan } \\
\text { berbagai skala untuk memenuhi } \\
\text { tuntutan kerja }\end{array}$ \\
$\begin{array}{l}\text { File disimpan dalam berbagai format } \\
\text { sesuai dengan prosedur operasi standar }\end{array}$ \\
$\begin{array}{l}\text { Menghubungkan entiti dengan } \\
\text { pemesanan barang/daftar bagian untuk }\end{array}$ & $92,5 \%$ \\
memenuhi tuntutan pekerjaan \\
Titik acuan dapat ditampilkan sesuai & $77,5 \%$
\end{tabular}




\begin{tabular}{lll}
\hline \multicolumn{2}{c}{ Kompetensi } & $\begin{array}{c}\text { Tingkat } \\
\text { Relevansi }\end{array}$ \\
\hline $\begin{array}{l}\text { tuntutan kerja } \\
\text { Menyimpan file/berkas }\end{array}$ & dalam & $85 \%$ \\
berbagai format untuk penggunaan & \\
kembali sesuai prosedur operasi & \\
standar & & \\
Mengeluarkan data sifat fisik benda 3D & $82,5 \%$ \\
sesuai tuntutan kerja termasuk volume, \\
masa dan pusat masa
\end{tabular}

Tabel 6. Kompetensi Cukup Relevan

\begin{tabular}{|c|c|}
\hline Kompetensi & $\begin{array}{l}\text { Tingkat } \\
\text { Relevansi }\end{array}$ \\
\hline $\begin{array}{l}\text { Gambar baku dikostumasi dengan } \\
\text { prosedur operasi standar }\end{array}$ & $66,3 \%$ \\
\hline $\begin{array}{l}\text { Macro dikembangkan ke prosedur } \\
\text { operasi standar }\end{array}$ & $65 \%$ \\
\hline $\begin{array}{l}\text { Data tambahan dihasilkan dari gambar } \\
\text { untuk memenuhituntutan pekerjaan } \\
\text { termasuk luas, panjang, sudut dan } \\
\text { keliling }\end{array}$ & $66,7 \%$ \\
\hline Menampilkan sistem koordinat & $66,7 \%$ \\
\hline $\begin{array}{l}\text { Dapat menampilkan pandangan sesuai } \\
\text { tuntutan kerja }\end{array}$ & $65 \%$ \\
\hline Membuat entiti dalam ruang 3D & $62,5 \%$ \\
\hline Memanipulasi entiti dalam ruang 3D & $62,5 \%$ \\
\hline $\begin{array}{l}\text { Membuat bentuk 3D surface termasuk } \\
\text { bentuk ruled dan revolved seperti } \\
\text { tuntutan kerja }\end{array}$ & $70 \%$ \\
\hline $\begin{array}{l}\text { Memodifikasi model 3D seperti tuntutan } \\
\text { kerja }\end{array}$ & $71 \%$ \\
\hline
\end{tabular}

Hasil penelitian ini terdapat kompetensi yang termasuk dalam kategori cukup relevan yang menunjukan bahwa tidak semua kompetensi mata pelajaran TGM yang diajarkan di SMK Muhammadiyah 2 Jatinom dibutuhkan oleh seluruh kriteria industri. Industri yang digunakan untuk mencari data adalah industri yang bukan hanya bergerak di bidang manufaktur saja, melainkan dari bidang pengercoran logam, pengelasan dan manufaktur. Hal tersebut mempengaruhi hasil dari analisi data dalam penelitan ini.

Jika dilihat dari hasil angket penelitian menurut tempat praktik kerja industri SMK Muhammadiyah 2 Jatinom, materi yang sudah diperoleh oleh siswa tentang mata pelajaran TGM 52,3\% materi tersebut sudah sesuai dengan kebutuhan di industri atau sangat relevan, sedangkan $47,7 \%$ materi yang diperoleh siswa termasuk kategori cukup relevan.

\section{SIMPULAN}

Kompetensi mata pelajaran TGM berdasarkan silabus kurikulum 2013 yang diajarkan di SMK Muhammadiyah 2 Jatinom cukup relevan dengan kompetensi yang dibutuhkan di industri manufaktur. Hal ini dapat dilihat dari persentase rata-rata relevansi kompetensi seluruh mata pelajaran tersebut sebesar $74,3 \%$.

Hasil angket penelitian menurut tempat praktik kerja industri SMK Muhammadiyah 2 Jatinom, materi yang sudah diperoleh oleh siswa tentang mata pelajaran TGM 52,3\% materi tersebut sudah sesuai dengan kebutuhan di industri atau sangat relevan, sedangkan $47,7 \%$ materi yang diperoleh siswa termasuk kategori cukup relevan.

\section{DAFTAR RUJUKAN}

Suharsimi Arikunto. (2013). Prosedur Penelitian: Suatu Pendekatan Praktik. Jakarta: Rieneka Cipta.

Badan Pusat Statistik. (2016). Tingkat Pengangguran di Indonesia. Diakses tanggal $18 \quad$ Maret 2017 https://www.bps.go.id/linkTabelStatis/vi ew/id/972.

Giesecke. et al. (2001). Gambar Teknik. (Terjemahan Rahim Gussito, Zulkifli Harahap). Jakarta: Erlangga.

Wahyu Nursalim. (2016). Relevansi Kompetensi Mata Pelajaran Produktif Pengelasan di SMK N 1 Sedayu dengan Kompetensi Las di Industri Daerah Istimewa Yogyakarta. Jurnal Pendidikan Vokasional Teknik Mesin. (Nomor 4 tahun 2016). Hlm. 275-280.

Rachmat Jati Puruasdi. (2016). Relevansi Mata Pelajaran Teknik Gambar Manufaktur di SMK Negeri 2 Pengasih Terhadap Kebutuhan Kompetensi di Industri. Jurnal Pendidikan Vokasional Teknik Mesin. (Nomor 8 tahun 2016). Hlm. 535-540. 
Sujiyanto. (2006). Menggambar Teknik Mesin.

Yogyakarta : Kanisius.
Syofian Siregar. (2011). Statistik Deskriptif untuk Penelitian. Jakarta : Rajawali Pers. 